\title{
Avaliação de atividades de risco na usina de tratamento de resíduos sólidos do Município de Manhumirim, Minas Gerais, Brasil
}

\section{Ronald Assis Fonseca*, Kleber Ramon Rodrigues, Leopoldo Concepción Loreto Charmelo, Alessandro Saraiva Loreto, Athos Alves Vieira}

Centro Universitário de Caratinga (UNEC). Av. Moacir de Matos, 49, Centro. Caratinga-MG. Brasil. (CEP 35300-047).*E-mail: ronald.ufv@hotmail.com.

Resumo. As questões ambientais vêm sendo destaque em todo mundo, não simplesmente por que o homem passou a respeitar a natureza, mas sim, porque os efeitos estão cada vez maiores e mais catastróficos. As ações antrópicas são as principais causas de degradação ambiental refletindo no consumo excessivo de recursos naturais e nos diversos tipos de poluição. É notório que o ser humano é extremamente consumista e despeja o seu resíduo sólido no ambiente em que vive. Neste contexto, os aterros sanitários, áreas que acumulam grandes quantidades de resíduos, representam uma alternativa. Entretanto, esses nem sempre recebem o tratamento adequado. O presente trabalho vai mostrar as consequências da implantação e operação da Usina de Tratamento de Resíduos Sólidos São Francisco de Assis, no Município de Manhumirim, na Zona da Mata de Minas Gerais, e busca apresentar as atividades desenvolvidas dentro da usina que por sua vez causam impactos significativos para o meio ambiente, principalmente na circunvizinhança; e propor medidas que buscam solucionar tais problemas. Sendo assim, a usina terá seu funcionamento de forma mais adequada, seguindo a legislação correta, garantindo a qualidade ambiental e a saúde dos trabalhadores em cada atividade desenvolvida e controlando ou minimizando os impactos ambientais.

Palavras-chave: Resíduos sólidos; Impactos ambientais; Tratamento de resíduos sólidos.

Abstract. Evaluation of risk activities in a solid waste treatment plant in the Municipality of Manhumirim, Minas Gerais State, Brazil. Environmental issues have stood out in the world, not only because man started respecting nature, but because the effects have become more prominent and even more catastrophic. Human action is the main cause of environmental degradation, leading to excessive consumption of natural resources and several types of pollution. Notably, human beings are extremely consumerists and get rid of solid waste in the environment in which they live. In this context, landfill, which is a place where a large amount of waste is dumped, become an alternative. However, sometimes, this waste does not receive appropriate treatment. Thus, this study aimed to show the consequences of the implementation and operation of the Solid Waste
Recebido:

03/02/2017

Aceito:

28/05/2017

Publicado:

30/06/2017

Acesso Aberto Artigo completo

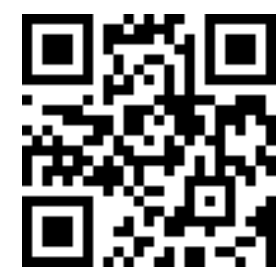

ORCID

(D) 0000-0002-7504-621X Ronald Assis Fonseca

(D) 0000-0002-9122-8419

Kleber Ramon

Rodrigues

(1) 0000-0003-1120-5979

Leopoldo Concepción

Loreto Charmelo

(D) 0000-0003-4757-6683

Alessandro Saraiva

Loreto

(D) $0000-0002-1214-4410$

Athos Alves Vieira 
Treatment Plant São Francisco de Assis, located in the Municipality of Manhumirim, in the Zona da Mata Mineira, Brazil. Also, it was sought to present the activities developed in the Plant, which cause significant impacts on the environment, particularly in its surroundings; in addition to proposing measures to solve these problems. Therefore, the Plant will operate in an adequate way, according to the correct legislation, ensuring a quality environmental and the workers' health in each developed activity, and controlling or minimizing the environmental impacts.

Keywords: Solid waste; Environmental impacts; Waste treatment.

\section{Introdução}

O crescimento populacional e econômico das últimas décadas desencadeou em alterações do padrão de vida da população, consequentemente trouxe problemas significativos ao meio ambiente. $\mathrm{O}$ problema do crescimento econômico desordenado veio acompanhado de um processo jamais visto pela humanidade, em que a utilização de grandes quantidades de energia e de recursos naturais, acabou configurando um quadro de degradação contínua do meio ambiente (Dias, 2011).

A comunidade em geral passou a consumir mais e consequentemente produzir grande quantidade de resíduos sólidos que são gerados em quantidades extremas para o atual panorama ambiental do planeta. Os processos de produção, as residências e outros setores geram grandes quantidades de resíduos que vão se acumulando e causando uma série de problemas, como contaminação da água e do solo, mau-cheiro, vetor de doenças, além da poluição visual. A gestão dos resíduos é um desafio para o mundo todo, desde grandes metrópoles, a pequenas empresas, e este problema só será solucionado com a participação de todos: governos, empresas e sociedade, buscando sempre alternativas de controle e mitigação aos danos ambientais (Castilhos, 2003).

Na busca por melhores soluções, o tratamento dos resíduos, surge como alternativa para minimizar a grande quantidade de resíduo gerado. As usinas de tratamento são vistas pela população, como a solução para a grande geração de resíduos sólidos (Mansor et al., 2010). Porém, o que a população leiga e mais preocupada com as questões ambientais desconhece é que as usinas de tratamento de resíduos sólidos também realizam processos e atividades que podem causar impactos ao meio ambiente.

Sendo assim, torna-se de grande importância apresentar para a população as atividades que podem causar risco ao meio ambiente e saúde, desenvolvidas em uma usina de tratamento de resíduos sólidos e descaracterizar a visão ecologicamente correta que a população impõe em querer buscar soluções rápidas de combate aos danos ambientais, de um empreendimento que visa à melhoria da qualidade do meio ambiente e consequentemente da qualidade de vida.

O trabalho visa a identificar as atividades de risco na Usina de Triagem e Tratamento de Resíduos Sólidos de Manhumirim, através de tabelas de inspeção para atividades de risco e apresentar os dados à população, mostrando as consequências dos impactos causados ao meio ambiente e como controlá-las e mitigá-las caso venham a acontecer.

\section{Um novo cenário mundial}

Quando o homem percebeu que poderia se instalar em determinadas áreas e a partir dali construir suas moradias e usufruir dos recursos a sua volta, iniciou-se em passos curtos a grande alteração ambiental que conhecemos hoje. Nos primórdios, ao longo do Rio Nilo, no continente africano, foram surgindo às primeiras comunidades, que viam um rio com grandes oportunidades para a sobrevivência, sem precisar se deslocar durante o ano para diversas outras regiões 
(Mazoyer, 2010), enfim, poderiam se instalar, aproveitar as épocas de cheias, trazendo para perto um solo fértil e excelente para o plantio.

O homem aperfeiçoou a adaptação, não só ao meio, mas também as tecnologias. Ainda mais após a Revolução Industrial, o homem deixando o campo, para morar nas cidades, o crescimento populacional desordenado, acarretando no crescimento tecnológico. O surgimento de grandes indústrias é um dos grandes responsáveis pelo novo cenário mundial no que diz respeito a meio ambiente (Dias, 2011).

\section{Resíduos sólidos e tratamento}

Os resíduos sólidos são quaisquer materiais que após uso, não possuem mais valor, e podem causar algum tipo de alteração ao meio ambiente, conhecidos de forma popular como lixo (Granziera, 2009).

Qualquer setor, empresa, indústria de bens e de serviços geram grandes quantidades de resíduos, sendo estes depositados em latões de lixo para que sejam removidos e enviados ao lixão onde será disposto sem quaisquer precauções. Parte do resíduo que não terá utilidade, será aterrado ou incinerado. $\mathrm{O}$ tratamento depende de cada usina ou aterro em que o resíduo será destinado.

\section{sólidos}

\section{Usina de tratamento de resíduos}

O Município de Manhumirim, localizado na Região da Zona da Mata de Minas Gerais, possui cerca de $27 \mathrm{mil}$ habitantes, cuja principal atividade econômica é a monocultura do café (IBGE, 2010).

O município possui uma usina de tratamento de resíduos sólidos, onde é realizada a coleta por meio de caminhões, sem a separação adequada dos resíduos no mesmo, posteriormente o resíduo é enviado para a usina onde acontece a separação. $\mathrm{O}$ resíduo orgânico é separado e colocado em um pátio, a céu aberto onde é deixado até que entre em processo de decomposição e posteriormente encaminhado para ser utilizado em forma de adubo em canteiros de jardins pelo próprio município. Os demais resíduos são separados de acordo com suas características, papel, plástico, garrafas PET, vidro, metal, entre outros. Os materiais são depositados em baias, que são pequenos espaços em um galpão para armazená-los. Depois de separados os materiais são prensados e empacotados para serem vendidos para outras empresas que utilizam estes materiais para produção de novos produtos.

A Lei $n^{\circ}$ 12.305/2010 (Brasil, 2010), que instituiu a Política Nacional de Resíduos Sólidos (PNRS), constitui-se em instrumento essencial na busca de soluções para um dos mais graves problemas ambientais do Brasil, a má destinação dada aos resíduos sólidos, impondo a necessidade de substituir os lixões a céu aberto por aterros sanitários como medida de proteção ambiental.

O art. 54, do PNRS, estabelece que a disposição final ambientalmente adequada dos rejeitos, observado o disposto no $\S 1^{\circ}$, do art. $9^{\circ}$, da lei, deverá ser implantada em até quatro anos após a data de sua publicação. Significando a decretação do fim dos lixões no Brasil até o ano de 2014 e sua substituição por aterros sanitários em todos os municípios brasileiros.

A Usina de Tratamento São Francisco de Assis, localizada no Município de Manhumirim, era utilizada até início de 2014 também como lixão, onde após o resíduo passar pelas esteiras para segregação dos materiais, o restante do material era enterrado em torno da usina, acarretando os problemas recorrentes deste tipo de disposição final inadequada para os resíduos sólidos, como por exemplo muitos animais circulando pela região, podendo funcionar como vetores de várias doenças, além, da liberação de chorume e de gases decorrentes da decomposição e a possível contaminação dos lençóis freáticos. A região onde a usina se encontra é uma zona rural com diversos moradores que são produtores de cafés e outros grãos.

Deve-se entender que, de acordo com art. $3^{\circ}$, inciso VIII, da Lei $n^{\circ}$ 12.305/2010 (PNRS) (Brasil, 2010), a disposição final ambientalmente adequada dos resíduos sólidos é a distribuição ordenada de rejeitos em aterros sanitários, 
observando normas operacionais específicas de modo a evitar danos ou riscos à saúde pública e à segurança e a minimizar os impactos ambientais adversos. Significa a obrigatoriedade de implantação de aterros sanitários em substituição aos lixões e aterros controlados. $\mathrm{O}$ art. $9^{\circ}, \S 1^{\circ}$ da PNRS também estabelece que poderão ser utilizadas tecnologias visando à recuperação energética dos resíduos sólidos urbanos, desde que tenha sido comprovada sua viabilidade técnica e ambiental e com a implantação de programa de monitoramento de emissão de gases tóxicos aprovado pelo órgão ambiental.

\section{ambientais}

Atividades, aspectos e impactos

A Usina de Tratamento São Francisco de Assis, como qualquer empreendimento, setor ou empresa, realiza diversas atividades para obter o seu produto final, para tal, utilizam-se os recursos naturais, energia, além de gerar resíduos.

A partir das definições da ISO 14001-2004, o termo "aspecto ambiental” é considerado qualquer elemento das atividades, produtos e serviços de uma organização que pode interagir com o meio ambiente. Ele é originado do consumo de insumos ou da geração de resíduos nas diversas atividades de uma organização. Por outro lado, Impacto Ambiental é definido como qualquer modificação do meio ambiente, adversa ou benéfica, que resulte, no todo ou em partes, das atividades, produtos e serviços de uma organização, sendo assim, o impacto ambiental é uma consequência do aspecto ambiental (ABNT, 2008).

Com base nas definições descritas, o diagrama na Figura 1 indica a relação de causa e efeito existente entre atividades, produtos, aspectos e impactos ambientais utilizados neste trabalho.

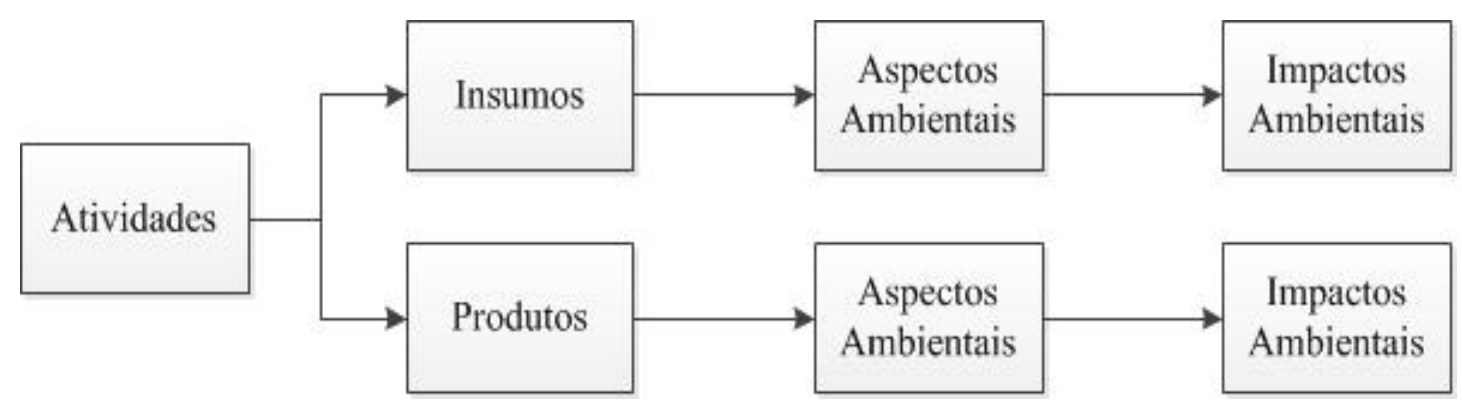

Figura 1. Diagrama de atividades, aspectos e impactos.

Como descrito no diagrama, uma atividade, onde haverá entrada de insumos e saídas de produtos, pode gerar um ou mais aspectos, que são elementos da atividade, e este causar um ou mais impactos, que modificam o meio ambiente. Desta forma, para identificar os impactos ambientais dentro de uma usina de tratamento de resíduos sólidos é necessário primeiramente realizar a identificação das atividades, que consequentemente, poderão causar um aspecto, essas atividades são ditas como atividades de risco, podendo causar algum transtorno para o meio ambiente ou a saúde dos trabalhadores e a população ao entorno da usina. Este transtorno é um impacto ambiental, que pode ser contaminação, poluição ou outro dano nocivo a saúde ou ao meio ambiente (Leite, 2008).

\section{Materiais e métodos}

Este trabalho foi realizado com visitas à Usina de Tratamento de Resíduos Sólidos São Francisco de Assis, no Município de Manhumirim, Estado de 
Minas Gerais, para a avaliação de atividades de risco que poderiam levar a um impacto ambiental, utilizando tabelas descritivas de inspeção, de acordo com Leite (2008), identificando as atividades, os possíveis riscos, os impactos causados ao meio ambiente e as consequências para a saúde e o bem estar da circunvizinhança.

Posteriormente, foram apresentadas medidas de controle para impedir que o impacto ocorra.

A tabela foi utilizada para listar as atividades desenvolvidas dentro da Usina de Tratamento São Francisco de Assis, permitindo ordenar estas atividades, que incluem transporte e tratamento dos resíduos, bem como o seu armazenamento e separação, preenchidos no campo ATIVIDADE. No campo RISCO, foram descritos possíveis riscos de acidentes e de contaminação que podem ocorrer em cada uma das atividades. Toda atividade tem aspectos significativos que devem ser considerados, ou seja, a causa ou a fonte do possível dano ambiental ou acidente que venha a ocorrer, estes foram descritos no campo CAUSA/EFEITO.
O campo MEDIDA DE CONTROLE, propõe as alternativas e tecnologias que podem ser utilizadas para controlar ou mitigar os impactos ambientais. Por fim, o campo OBSERVAÇÃO, lista alguns problemas recorrentes na usina, as condições de trabalho e dos equipamentos.

\section{Resultados e discussão}

A seguir são apresentadas imagens da Usina de Reciclagem São Francisco de Assis e algumas das atividades desenvolvidas no setor.

A Figura 2 retrata o pátio da usina de tratamento, onde os resíduos chegam e são encaminhados para uma esteira de separação. Neste pátio estão algumas categorias de resíduos separados e outros misturados, como por exemplo o alumínio e cobre que são armazenados ao ar livre, assim como as bags, grandes sacolas de armazenamento, como resíduos separados, além do material orgânico que é despejado no terreno, para a compostagem.

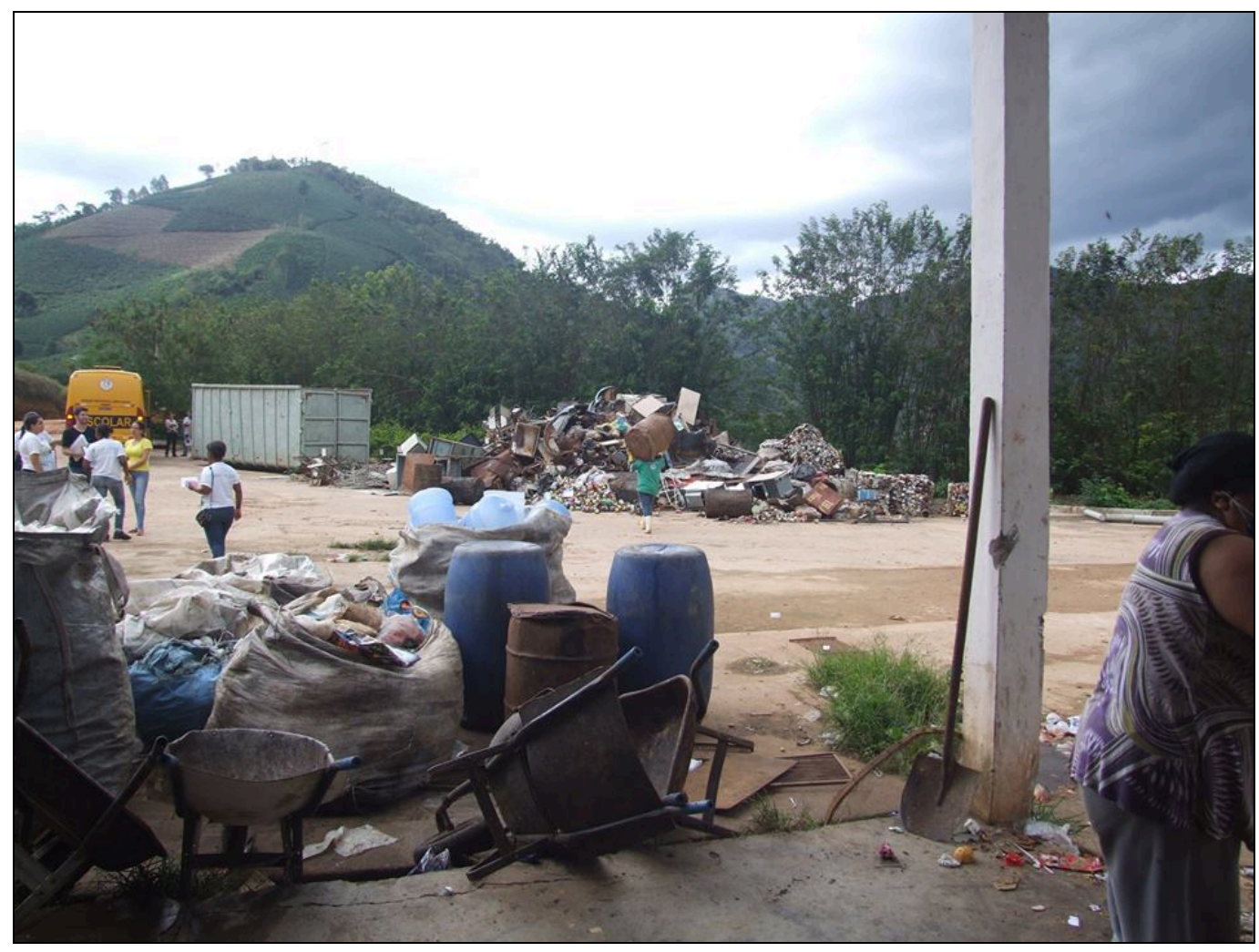

Figura 2. Pátio da Usina de Tratamento de Resíduos Sólidos de Manhumirim. 2015. 
Os funcionários higienizam a área onde serão separados os resíduos em categorias, para depois serem armazenados. A Figura 3 mostra que os funcionários estão usando alguns dos EPI's (Equipamentos de Proteção Individual), mas ainda de forma incompleta.
A usina possui um galpão, com as chamadas baias, para a separação dos resíduos que serão comercializados, onde são separados por categorias, por exemplo, plástico, alumínio, embalagens tetra-pak de caixas de leite e outros produtos.

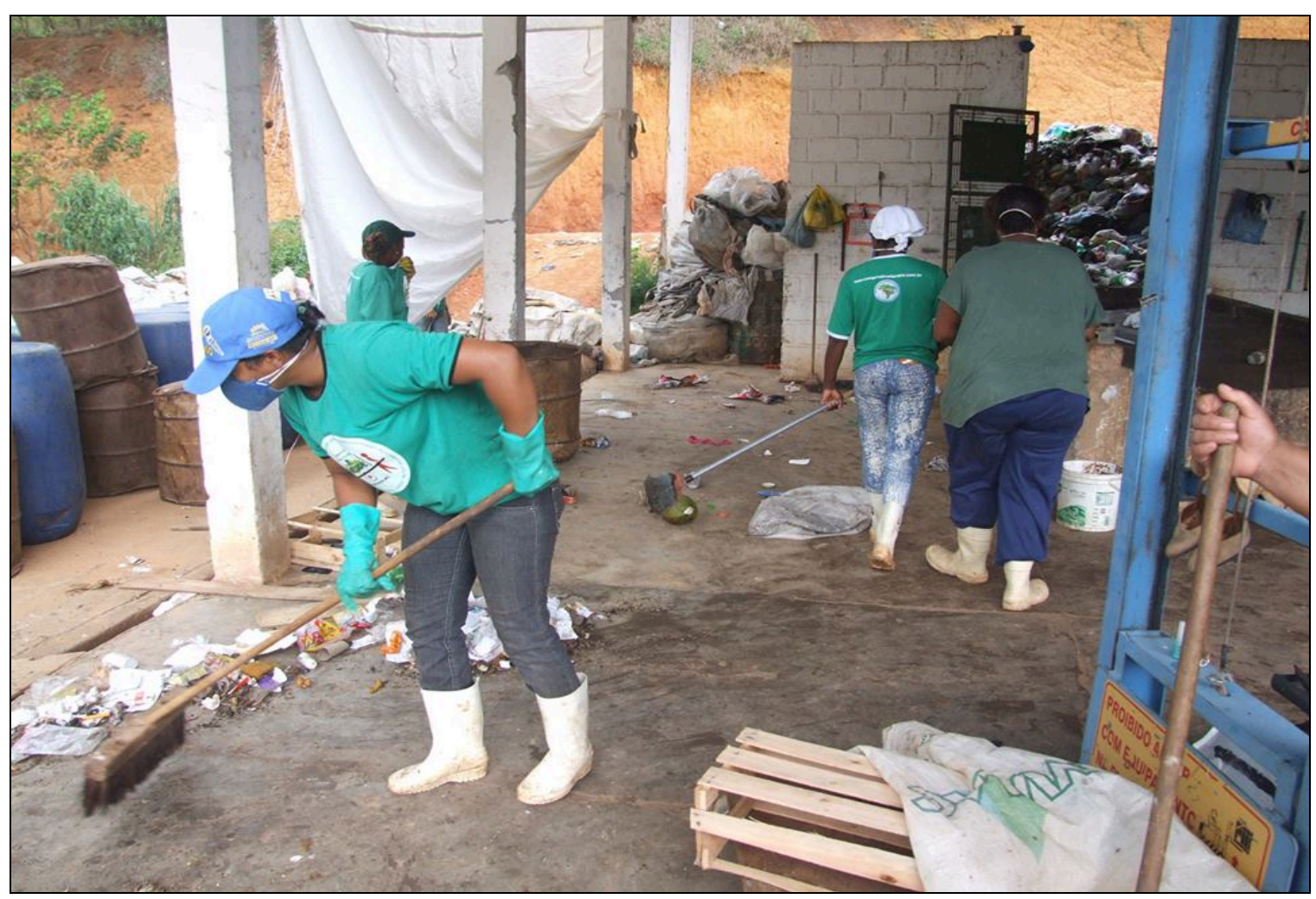

Figura 3. Higienização da área de separação dos resíduos. 2015.

A Figura 4 indica o local onde os rejeitos, ou seja, aquele material que não possui uso e necessita de uma destinação final, serão aterrados. Foi possível perceber que a área não atende aos padrões exigidos pela legislação, mostrando o cenário em que se encontram os rejeitos, que são despejados sobre o solo, até que se encham os espaços e logo após, uma camada de terra será jogada por cima, e aguarda o caminhão chegar para repetir o processo. Podemos observar que o chorume, líquido que escorre fica exposto e percola o solo em direção ao lençol freático, podendo alcançar os rios da região que abastece os moradores em torno da usina.
Através das imagens e das visitas in locu foi possível identificar diversas atividades dentro da usina que não são realizadas de forma correta, tomando todos os cuidados de prevenção a acidentes. Estas atividades possuem aspectos que resultam em impactos para a população ao entorno, como por exemplo, contaminação do solo e da água pelo liquido que escorre do resíduo em decomposição, conhecido como chorume, a contaminação do ar por gases que são liberados, além da veiculação de animais e outros microrganismos que oferecem risco à saúde da população. 


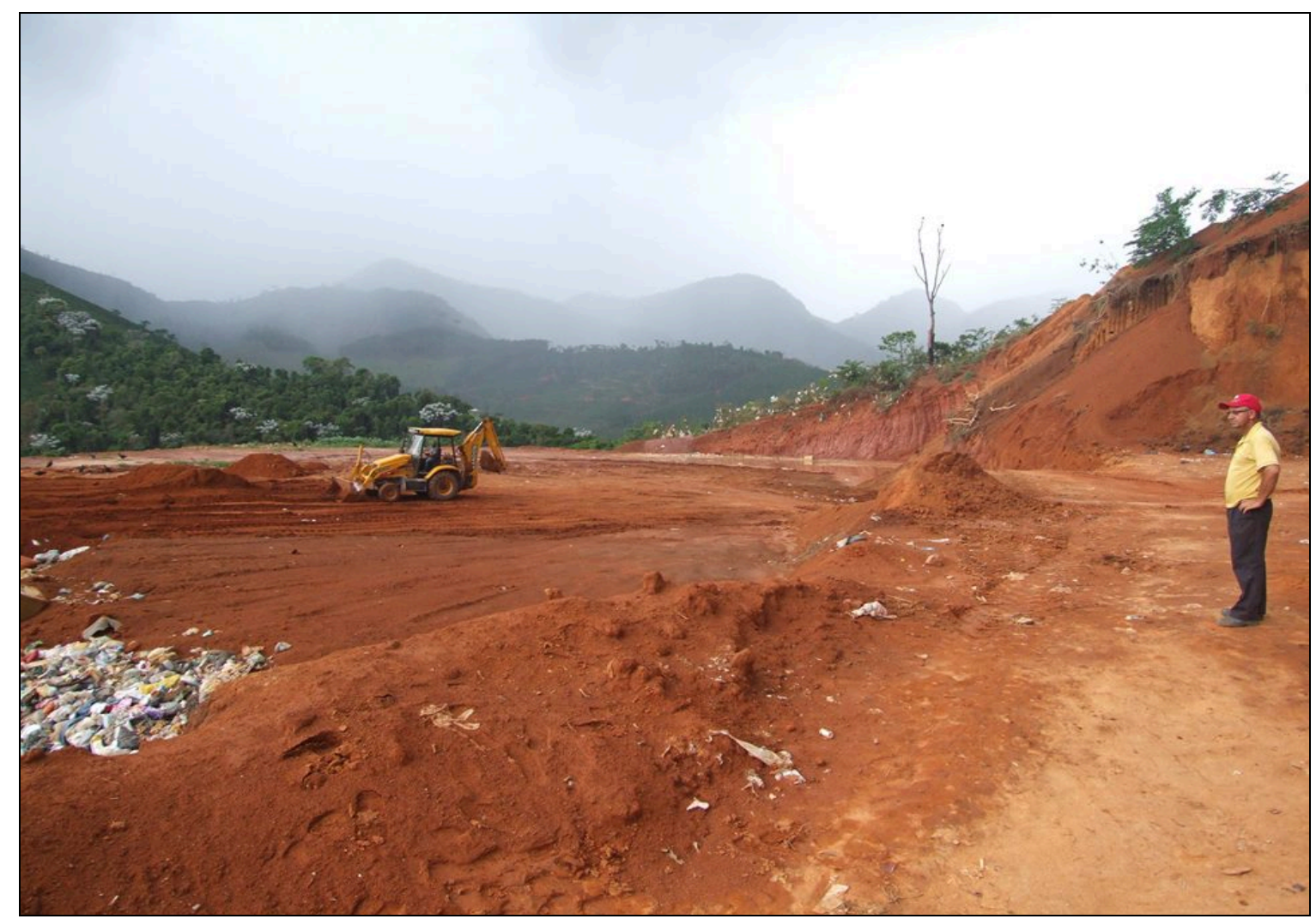

Figura 4. Lixão da Usina de Tratamento de Resíduos. 2015.

Com as constatações e visitas realizadas na Usina de Tratamento de Resíduos Sólidos São Francisco de Assis, em Manhumirim, foi criada uma tabela de inspeção que descreve as atividades, os riscos, a causa e efeito e as medidas de controle e com esses resultados da Tabela 1 , foi possível identificar que todas as atividades descritas podem trazer risco ao meio ambiente e a saúde da população, como por exemplo, a contaminação da água que abastece a comunidade próxima a usina, pelo líquido que escorre da decomposição do resíduo.

\section{Considerações finais}

Embasado na pesquisa de campo foi possível verificar o impacto que uma usina de tratamento pode causar ao meio ambiente e através da Tabela 1, foi possível identificar as atividades e os riscos.
Podemos perceber que o homem tem a extrema capacidade de adaptação ao meio em que vive, o grande e maior problema é que sua adaptação requer a alteração do meio em que ele vive, e isso sempre acarretou no que conhecemos hoje como problemas ambientais, danos ambientais, degradação ambiental e impactos ambientais. Compramos, produzimos, sujamos e buscamos uma adaptação no meio para receber nossa sujeira, nosso lixo, nossos resíduos que devem ser eliminados de alguma forma, pois se o homem busca sempre o conforto e melhores condições de vida, cabe a ele destinar o próprio resíduo, mas nem sempre de forma adequada (Lima, 2002). Observamos isso com a grande quantidade de lixo que é gerado a cada dia e a dificuldade em destiná-lo. Como alternativa "adequada" surgem os aterros sanitários, uma opção para descartar nossos resíduos, 
longe de nossas casas, para que nós não soframos os impactos de forma direta. O grande problema, porém, não está apenas no acumulo de resíduos nos aterros, mas sim em todo o processo dentro de uma usina de resíduos, que através de suas atividades podem causar impactos ambientais de ordem significativa para o meio ambiente e para a população circundante.

Tabela 1. Atividades de risco da Usina de Tratamento de Resíduos Sólidos São Francisco de Assis, no Município de Manhumirim-MG.

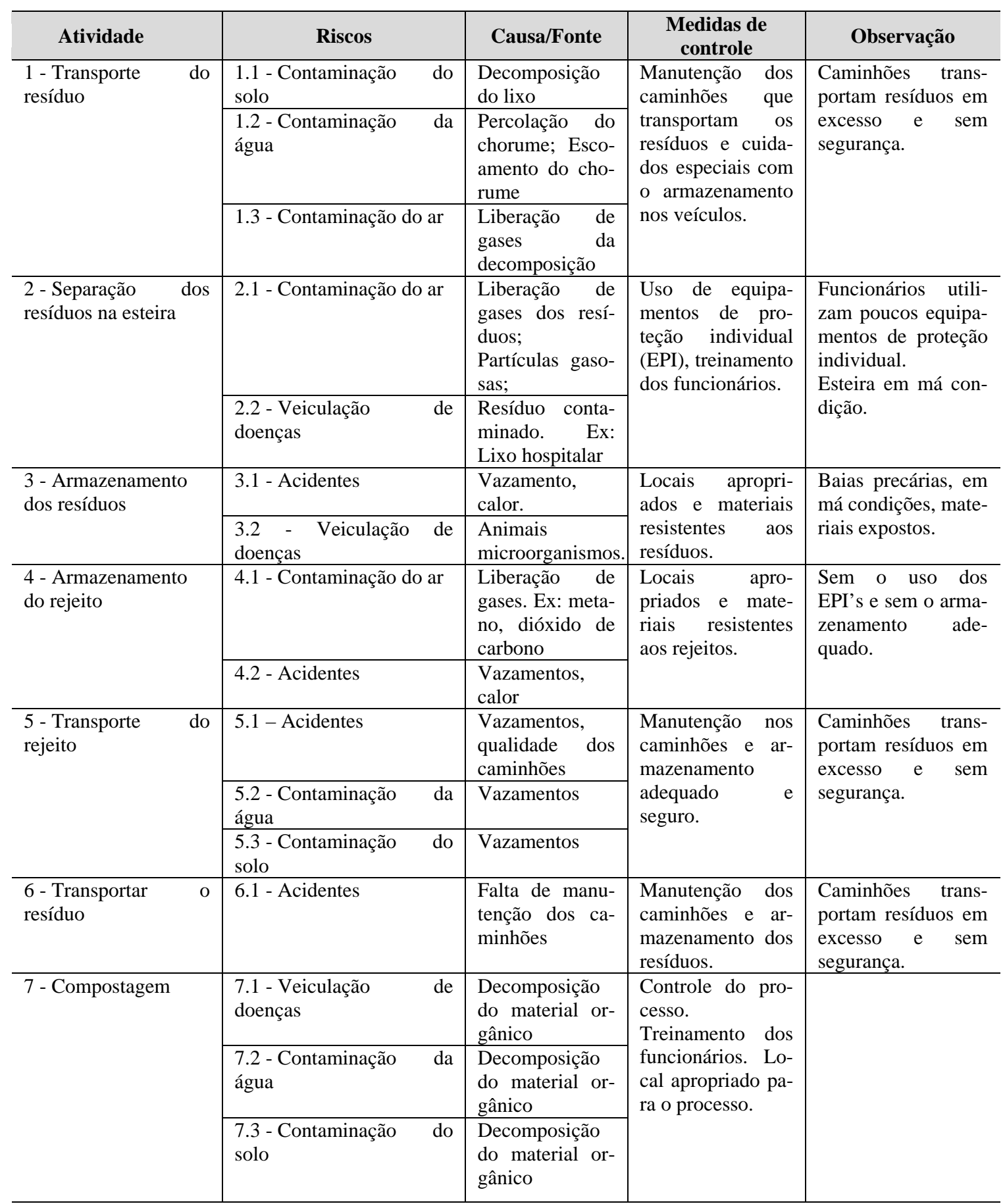


São necessárias alternativas que visam a controlar estes impactos ou impedir que eles ocorram, pois mesmo se tratando de uma alternativa ecológica e sustentável para a destinação correta, o mesmo pode causar problemas para o meio ambiente e a comunidade ao entorno, entretanto, não são necessárias apenas alternativas eficientes, mas sim uma maior sensibilização, tanto do governo, município, funcionários e a própria comunidade para que a educação ambiental seja permanentemente aplicada a fim de mostrar os efeitos que o homem causa a sua casa.

\section{Declaração de conflito de interesses}

Os autores declaram não haver conflito de interesses.

\section{Referências}

ABNT - Associação Brasileira de Normas Técnicas. NBR 1000:2004 - Resíduos sólidos Classificação. Rio de Janeiro: ABNT, 2004.

ABNT - Associação Brasileira de Normas Técnicas. NBR ISO 14001:2008. Sistemas de Gestão Ambiental - Requisitos com orientações para uso. Rio de Janeiro: ABNT, 2008.

Brasil. Lei $\mathrm{n}^{\circ}$ 9.605, 12 de fevereiro de 1998. Dispõe sobre as sanções penais e administrativas derivadas de condutas e atividades lesivas ao meio ambiente, e dá outras providências. Disponível em: <http://www.planalto.gov.br/ccivil_03/leis/L960 5.htm>. Acesso em: 21 nov. 2016.

Brasil. Lei $\mathbf{n}^{\mathbf{0}}$ 12.305, de 2 de agosto de 2010. Institui a Política Nacional de Resíduos Sólidos; altera a Lei $\mathrm{n}^{\circ}$ 9.605, de 12 de fevereiro de 1998; e dá outras providências. Disponível em: <http://www.planalto.gov.br/ccivil_03/_ato2007 -2010/2010/lei/l12305.htm>. Acesso em: 21 nov. 2016.
Castilhos Junior, A. B. (Coord.). Resíduos sólidos urbanos: aterro sustentável para municípios de pequeno porte. Rio de Janeiro: ABES/RiMa, 2003.

Dias, R. Gestão ambiental: responsabilidade social e sustentabilidade. 2. ed. São Paulo: Atlas, 2011.

Granziera, M. L. M. Direito ambiental. São Paulo: Atlas, 2009.

IBGE - Instituto Brasileiro de Geografia e Estatística. Censo demográfico 2010. Cidades. Minas Gerais. Manhumirim. Disponível em: $<$ http://cod.ibge.gov.br/HCF>. Acesso em: 21 nov. 2016.

Leite, S. F. L. Levantamento de aspectos e impactos ambientais. Belo Horizonte: SENAC Minas, 2008.

Lima, J. D. Gestão dos resíduos sólidos urbanos no Brasil. João Pessoa: ABES, 2002.

Mansor, M. T. C.; Camarão, T. C. R. C.; Capelini, M.; Kovacs, A.; Filet, M.; Santos, G. A.; Silva, A. B. Resíduos sólidos. São Paulo: SMA, 2010. (Cadernos de Educação Ambiental, 6).

Mazoyer, M.; Roudart, L. História das agriculturas no mundo: do neolítico à crise contemporânea. São Paulo: Editora UNESP; Brasília, DF: NEAD, 2010. 